\title{
Flexible Parsing
}

\author{
Phil Hayes and George Mouradian \\ Computer Science Department, Carnegie-Mellon University
}

Pittsburgh. PA 15213, USA

\begin{abstract}
'
When people use natural language in natural settings, they often use it ungrammatically, inissing out or repeating words. breaking-oit and restarting. speaking in tragments, etc.. Their human listeners are usually able to cope with these deviations with little difficully. If a compuler system wishes tc accept natura language input from its users on a routine basis, it must display a similar indifference. In this paper. we outline a set of parsing flexibilities that such a system should provide. We go on to describe Flexp. a boltom-up pattern-Inatching parser that we have designed and implemented to provide these flexibilities for restricted natural language input to a limited-domain computer system.
\end{abstract}

\section{The Importance of Flexible Parsing}

When people use natural language in natural conversation, they often do not respect grammatical niceties. Instead of speaking sequences of grammatically well-formed and complete sentences. people often miss out or repeat words or phrases, break off what they are saying and rephrase or replace it, speak in tragınents. or use otherwise incorrect grammar. The lollowing exainple conversation involves a number of these grammatical deviations:

$$
\begin{aligned}
& \text { A: I wailt ... can you send a memo a message to to Smith } \\
& \text { B: Is llail John or Jolm Simith or Jim Smith } \\
& \text { A: Jim }
\end{aligned}
$$

Instead of being unable or refusing to parse such ungrammaticality. hunian listeners are generally unperturbed by it. Neither participant in the above example, for instance. would have any dilficulty in following the conversation.

If computers are ever to converse naturally with humans. they must be able in marso their input as Hexibly ant robustly is thumatus ido. While consiterable advances have been made in recent years in applied natural language processing. few of the systems thit have been constructed lave paikl sulficient attention in the kinds of deviation that will inevitably occur II their "wiput if they are used il a natural enviromment. In many cases, if the user's input does not coniorm to the system's yrammir, an indication of incompreinension followed by a request to repluase may be the best he (:a) expext. Wo boliew: Hatt such inllexibility in parsing severely linits the practicality of uatural language compuler interlinces. and is a inajor reason why natural language has yet to find witle acceptance in such applications as database retrieval or interactive command languages.

In this paper, we report on a flexible parser, called Flexp, suitable for use with a restricted natural language interface to a limited-domain computer system. We describe first the kinds of grammatical deviations we are trying to deal witl. then the basic design decisions for FlexP with justification for them based on the kinds of problem to be solved, and finally inore details of our parsing system with worked examples of its operation. These examples.and most of the others in the paper, represent natural language input to an electronic mail system that we and others [1] are constructing as nart of our research on user interfaces. This system employs Flexp to parse its input.

\section{Types of Grammatical Deviation}

There are a number of distinct types of granmatical deviation and not all tyne:s are foum in all types of communication siluation. In this soction. we lirst define the restricted type of communication situation that we will be concerned with, that of a limited-domain computer system and its user coinmunicating via a keyboard and display screen. We then present a taxonomy of graminatical deviations common in this context, and by implication a set of parsing flexibilitios needed to cleal with them.

\subsection{Communication with a l.imited.Domain System}

In the remainder of this paper. we will focus on a restricted type of commumication situation. that between a limited-domain system and its user, and on the pirsing flexibilities needed by such a system to cope with the user's inevitable grammatical deviations. Examples of the type of system we have in mind are data-base retrieval systems. electronic mail systems. Inedical dliaynosis systems, or any systems operating in a domain so restricted that they can complotely understand any relevant input a user might provide. In short, exactly the kind of system that is normally used for work in applied natural lanuuage processing. There are several points to be made.

First. although wuch systems can be expected to parse and unclerstand anything relevant to their domain. their users cannot be expected to confine themselves to relevant input. As Bolorow el. al. $|2|$ nolu. users ollen explait llutir uncterlying motivations or otherwise justily their

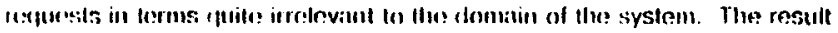
is that such systems cannot expect to parse all thi:i InIul even with lite use of flexible parsing lechniques.

Secomily, a flexible parser is just purt of the conversational component of such a system. and cannot solve all parsing probtems by itself. For example. il a parses can extract two coherent fragunents from an olleerwise incomprehensible input, the decisions about what lle system should next must be made by another component of the system. A decision on whether to jump to a conclusion about what the user intended, to present him with a set of alternative interpretations. or to profess total confusion, can only be made with information aboul the history of the conversation, beliels aboul the user's goals, and measures of plausibility for any given action by the user. See $[7]$ for more discussion of this broader view of graceful interaction in man-machine communication. Suflice it to say that we assume a flexible parser is just one component of a larger system, and that ally incomprehensions or ambiguities that it linds are passed on to another component of the system with access to higher-tevel information. putting it in a better position to decide what to do next.

Finally, we assume that, as usual for such systems, input is typed, ralher than spoken as is normal in human conversations. This simplifies low-level processing tremendously because key-strokes unlike speech wave-fornis are unambiguous. On the other hand, problems like misspelling arise. and a flexible parser cannot assume that segmentation into words by spaces and carriage returns will always be correct. However, such inpul is still one side of a conversation, rather than a polished text in the manner of most written material. As such, it is likely to contain many of the same type of errors normally found in spoken conversations.

\subsection{Misspelling}

Misspelling is perliaps the most common form of grammatical deviation in written language. Arcordingly, it is the form of ungrammaticality that has been deall with the inost by language processing systems. PARAY | $11 \mid$. I.ITER |B|. aUMI numerous other systems have tried to correct missuelt imput trom their users.

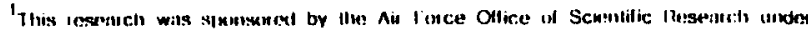

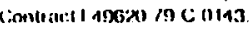


An ability to correct spelling implies the existence of a dictionary of correctly spelled worts An input word not found in the dictionary is assumed to be misspelt and is conpared against each of the dictionary words. If a dictionary word comes close enough to the input word according to some criteria of lexical inatching, it is used in place of the input word.

Spelling correction may be altempted in or out of context. For instance. there is only one reasonalde correction for "retavent" or lor "seperate" but for an mint like " "u" some kund of contu?xt is typic:ally necessary as in "I'll see you un April" of "he was shot wilh the stoien un." in elfect. context can be used to reduce the size of the stictumary to be searched for correct words. This both makts the search inure tificient and reduces the mossibilily of mulnole matcihus of the mput aganist the dictionary. The LIFEA $|B|$ syslem uses the strong contatramts typically movided by its semanlic yllmmil in llis way to rextuce the range of possibilities for spelling correction.

A particularly troublesome kind of spelling error results in a valid word diflerent from the one intended, as in "show me on of the messages". Clrialy. sucht in error can only be correc:terl through commirison against a contextually deterinined vocabulary.

\subsection{Novel Words}

Even accomplished users of a language will sometimes encounter words they do not know. Such situations are a test of their language laarning skills. If one dirtn't know the word "lawn", one could at least decide it was a colour from "a fawn coloured swealer". If one just knew the wurd as reterning lo a young deer, one mihl cuiclude that il was beny used to mean the colour of a young deer. In general. beyond making direct interences about the role of unknown words from their immediate context. vocabulary learning cin require arbitrary amounts of real-worid knowledge and mference. and this is certainiy beyond the capabilities of present day artificial intelligence lechniques (though see Carbonell [4] for work in this direction).

There is. however, a very common special subclass of novel words that is well within the capabilities of present day systems: unknown proper numes. Given an appropriate context. either sentential or discourse. it is relatively straighttorward to parse unknown words into the names of people. places. efc. Thus in "send copies to Moledeski Cliiselov" it is reasonable to concitude from the local context that "Moledeski" is a first nume. "Chisetov" is a surname. and loyether they identily a person (the intended recipinnt of the copies). Strategues like this were used in the POLITICS [5]. FRUMP [6], and PARRY [1 1] systems.

Since novel words are by definition not in the known vocabulary. how cail a parsiny system distinguish them from inisspellings? In most cases. the novel words will not be close enough to known words to allow successtut correction, as in the above example. but this is not always true: all unknown first name of "Al" could easily be corrected to "all". Conversely. it is not sale to assune that unkulown words it contexts which allow proper names are really proper names as in: "send copies to al managers". In this example. "al" probably should be corrected to "all". In order to resolve such cases it mily be necessary to check igainst a list of referents tor proper names. if this is known. or otherwise to consider such factors as whether the inuliat letters of lhe wortis are capilalized.

As far as we know. no systoms yet consiructed have inforgrated their hilndling of misspch words and unknown. prober names to the degree oullined atoves. However, the COOP $|9|$ systtom allows systmunatic access to a data base continimu promer names without the mext for inctusion of llie worets in the systern's marsing vocabulary.

\subsection{Erroneous segmenting markers}

Written text is segmented into words by spaces and new lines. and into higher level units by commas. periods and other punctuation marks. Buth classes. especially the second, may be omited or inserted speciousiy. Spoken language is atso segmented, but by the quite dilferent markers of stress, interaction and noise words and phrases; we will not consider those further here.

Incorrect seymentation at the lexical level results in two or more words being run together, as in "runtogether", or a single word being split up into iwo or more segments. as in "tog ether" or (inconveniently) "to get her". or combinations of these elfects as in "runto geth er". In all cases. it seems natural to deal with such errors by extending the spelling correction inechanism to be able to recognize target words as initia segments of uniknown words. and vice-versa. As far as we know. no current systems deal with incorrect segmentation into words.

The other type of segmenting error, incorrect puncluation, has a much broader unpact on parsing methodology. Current parsers typicatly work one sentence at a time. and assume that each sentence is terminated by an explicit end of sentence marker. A flexible parser must be able to deal with the potential absence of such a marker. and recogmize the sentence boundary regardless. It should aiso be able to make use of such punctuation il it is used correctly, and to ignore it it it is used incorrectly.

Instend of punctuation, inany interactive systems use carriage-return to indicate sentence termination. Missing sentence termınators in this case correspond to two sentences on one line, or to the typing of a sentence without the terninating return. while specious terminators correspond to typing a sentence on more than one line.

\subsection{Lioken-Oft and Restalled Ullerances}

In spoken language. it is very common to break off and restart all or part of an utterance:

I want to ... Could you lell ine the name?

Was the man --er-- the oflicial here yesterday?

Usually. such restarts are sighillerl in soine way. by "um" or "er". or inore explicitly by "lel's back up" or some simular phrase.

In written tanguage. such restarts do not normally occur because they are erased by the writer butore the reader sees them. Interactive computer syslems typically provide facilitics for their users to delete the last character. word, or cufretit lue us though il had never been typed. for the very purnose of altowing such restarts. Given these signals, the restarls are basy 10 detecl and interpreh. However, sometines users lanl to make use of these signals. Sometınes, for instance. input not containung a carriage-return can be spread over several lines by intermixing of input and output. A flexible parser should be able to make sense out. of "obvious" restarts that are not signalled, as in:

delete the show me all the messages from Smith

\subsection{Fragmentary and Otherwise Elliptical Input}

Naturally occuring language often involves utterances that are not complete sentences. Often the appropriateness of such fragmentary utterances devends on conversational or ohysical context as in:

A: Do you mcan Jim Smith or Fred Smith?

B: Jim

A: Send a message to Smith

B: OK

A: with copies to Jones

A flexibie parser must be able to parse such fragments given the appropriate context.

There is a question here of what such fragments should be parsed into. Parsing systems which have dealt with the problem have typically assurned If it such inputs are ellipses of complete sentences. and that their parsing involves finding that complete sentence. and parsing it. Thus the sentence corresponding to "Jim" in the example above would be "I mean Jim". Essentrally this view has been taken by the LIFER $[8 \mid$ and GUS [2] systems. An alternative view is that such fraginents are not ellipses of more complete sentences, but are themselves complete 
utterances yiven the context in which they occur, and should be parsed as such. We have taken thus view in our approuch to llexible parsing. as we will explain more fully below. Carboncll (personal communication) suggests a third view appropriate for some fricgments: that of an extended case framc. In the second example above. for instance. $A$ 's "with copies to Jones" forms a hallural pall of the calse Irame established by "seind a message to sintll" Yet amolner approach to fragment pausing is taken in the PLANES system [12] which aiways parsus in terıns of major fragments rather than complete ulterances. This technique relies on there bcing only one way to combine the fragments thus obtained, which may the a reasonable assumption for many linited domain systems.

Ellipses can also occur without royard to context. A lype that interactive systemns are patrliculiarly likely to lace is crypticness in which iufledes and other non-exisential words are omilled as in ":ilow messinges after June 17 "instead of the mure complete "show me all messikges diated alter June 17". Agjain. there is a question of whether to consider the crybtic input completo. wincti would meinl modilying llie systemis yrimmar, or whelher to consider it ellipticall. and complete it by using llexibie techmicyes to parse it agatinst the complete version as it exists in llie standard grammitar.

Other cominon forms of ellipses are associated with conjunction as in: John got up arul [John] brushed his teeth. Mary saw Bill and Bill [saw) Mary.

Fred recognized [ the building] and [Fred] walked towards the building.

Since conjunctions can support such a wide range of ellipsis. it is generally impractical to recognize such utterances by appropriate yraminar extensions. Ellorts to deal will conjunction have therefore depended on general mechanisms which supplement the basic parsing strategy, as in the LUNAR system [15], or wirch modify the graminar temporarily, as in the work of kwasny and Sondheimer $|10|$. We have nol attempled to deal wilh this type of ellipsis in our parsing system, and will not discuss further the type of llexibility it requires.

\subsection{Interjectod Phrases, Omission, and Substitution}

Sometimes people inleriect noise or other qualifying phrases into what is olherwise a normal grammatical llow as in:

\section{I want the messaye dated I think June 17}

Such interjections can be inserted at almost any point in an utterance, and so must be dealt with as they arise by flexible techniques.

It is relatively straightforward for a system of limited comprehension to screen out and ignore standard noise phrases such as "I think" or "as lar as I can tell". Morn troublesome are interiections that cannot be recognized by the system, as might for instance be the case in

Displity ljusit to relresil my meinory| the message daled June 17.

I want to see the message |as I lorgot what it said| clated June 17.

where the unrecognized interjections are bracketerl. A liexible parser should be able to ignore such intericctions. There is alwuys the chance that the unrecognized part was an important part of what the user was frying to say. but clearly. the groblems that arise from this cilluot be hamdled by a narser.

Oinissions of words (or phrases) from the input are closely related to cryptic input as discussed above, and one way of dealing with cryptic innul is to treat it as a set of omissions. However, in cryptic input only messtuntial intormation is inisser out. while it is conceivable that one coukd also omil essential inlormation as in:

\section{Displaty the mossage June 17}

Herc it is unclear whetler the speaker moans a messilge dated on dune 17 or belore June 17 or after June 17 (we assume that live system aldiessed

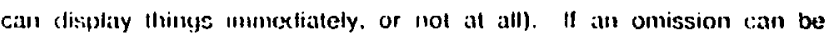
matrowed down in this way. the pirser should be atbe to generatio all the alternatives (lor combextual resolution of the iunticyuty or for the bisis of a aucstion to the user). It the onission can be narrowert down to one allernalive llen tlue mput was merely uratic.
Besides omitting words and phrases. people sometimes substitute incorrect or unintended ones. Often such substitutions are spelling errors and should be caught by the spelling correction mechanism, but sometimes they are inadvertent substitutions or uses of equivalent vocabulary not krrown to the system. This type of substitution is just like an omission except that there is an unrecognnized word or phrase in the place where the omitted input should have been. For instance. in "the inessage over June 17". "over" takes the place of "dated" or "sent after" or whatever elst is appropriate at that point. If the substitution is of vocabulary which is appropriate but unknown to the system, parsing of substituted worrls can provide the basis of vocabulary extension.

\subsection{Agreement Failure}

II is not uncommon for people to fail to make the appropriate agreement between the various parts of a noun or verb plirase as in :

I wants to send a messages to Jim Sinith.

The appropriate action is to ignore the lack of agreement. and Weischedel and Bluck [13] describe a melhod lor relaxing the predicates in an ATN which typically check for such agreements. However, it is generally not possible to conclucle locally which value of the inarker (number or person) for which the clash occurs is actually intended. We considered examples in which the disagreeinent involves more than inflections (as in "the messaye over Jume $\left.17^{\prime \prime}\right)$ in the section on substitutions.

\subsection{Idioms}

Idioms are phrases whose interpretation is not what would be obtained by parsing and interpreting them constructively in the normal way. They may also not adhere to the standard syntactic rules. Idioms must thus be parsed as a whote in a paltorn matching kind of mode. Parsers based purely on pattern unatching, like that of PARRY | 11 ]. theis are able to parse iclioms maturally. while others must either add a preprocessing phrase of pattern inatching as in the LUNAR system [15]. or mix specific patterns in will more gencral rules. as in the work of Kwasny and Sondheimer [10]. Semantic grammars $[3,8]$ provide a relatively natural way of mixing idiomatic and more general patterns.

\subsection{User Supplied Changes}

In nomal hemtaln conversaliom. once some!ling is said, it is said and cinnot be chimguxt, excupt indirectly by more words which refer back to the origmall ontes. In inleractively typead input. lliere is always the possitjility thatl a user may notice all error he has made and go back and correct it hmsell. willoul willing for the system to pursue its own. possitsly slow and ineflective. melloots of correction. Will approipriate editing lacilities. the user may do this willoul erasing intervening words, and, if the system is processing his input on a word by word basis. may

\section{An Approach to Flexible Parsing}

Most current parsing systems are unable to cope with most of the kinds of grammatical deviation outlined above. This is because typical parsing systems attempt to apply their grammar to their input in a rigid way, and since deviant input, by definition. does not conform to the gramınar, they are unable to produce any kind of parse for it at all. Altempts to parse more fiexibly have typically involved parsing strategies to be used after a top-down parse using an ATN $\{14\}$ or sinvilar transition net has falled. Such elforts include the ellipsis and paraphrise mechanisms of LIFER [B]. the predicate relaxation tecliniques of Weischedel and Black [13], and several of the devices for extending ATN's proposed by Kwasny and Sondheimer [10].

thus alter a word that the system has atready processed. A flexible parser inust be able to take advantage of such user provided corrections to unknown words, and to prefer thein over its own corroctions. It inust aiso be prepared to change its parse it the user changes a valid word to another different but equally valid word. 
We have constructed a parser. FlexP. which can apply its graminar to its input llexibly, and thus deal with the grammatical deviations discussed in the previous sociton. We sliould einphasize. however. that FlexP is designed to be used $m$ the unterlace to a restricted-domain system. As such, it is "htended to work Irom a domain-specific seinantic grammar. rather than one stutable for broader classes of input. Flexp thus does not embody a solution for llexible parsing of natural language in general. in describing FlexP. we will note those of its techmiques that seem unlikely to scale up to use with more conplex grammars with wider coverage.

We have adopted in FlexP an approach to flexible parsing based not on ATN's. but closer to the pattern-matching parser of the PARAY system [11]. possibly the inost robust parser yel constructed. Our approach is based on several design decisions:

- bottom up rather than top-down parsing: This aids in the parsing of fragmentary utlerances. and in the recmuntiom of interjections andi restarts.

- pattern matching: This is essential Ior idioms, ind also aids in the detection of omissions and substutulions in non-irliomatic phrases.

- parse suspension and continuation: The atbility to suspery al barse and litler resume it: processing is importan for intcriections. restarts. and non-explicit terminalions.

In the remaindier of this section we examine and justify these design decisions in more detail.

\subsection{Bottom-Up Parsing}

Our choice of a bottoin-up strategy is based on our need to recuunize isolated sentence traginents. If an utterance which would normally be considered only a fraginent of a coinplete sentence is to be recognized top-Hown. there are two approuches to take. First. the grammar can be altered so that the frayment is recoynized as a complete ulterance in its own right. This is undiesirabie because it can cause enormous expinsion of the grainmar, and because it becomes diflicult to decide whether a frayment appears in isolition or as part of a larger utterance, especially if the possibility of missing end of sentence markers also exists. The second option is for the parser to infer from the conversntional context what grammatical sub-category (or sequence of sub-calegories) the fraginent might fit into. and then to do a top-down parse from that sub-category. This essentially is the tactic user in the GUS $|2|$ alul LIFER $[8 \mid$ systems. This strategy is ctearly better than the first one. but has two probleins; first of prexlicting all possible sub-categories which might come next, and secondly. of inelficiency if a large number are preclicted. Kwasiy and Sondheimer $[10]$ use a combination of the two strategies by temporarily modifying an ATN grammar to accept tragment categories as complete utlerances at the tumes they are contextually predicted.

Bottoin-up parsing avoins the problem of prexlicting what sub-calegories imay occur. If a fragııent fitting a given sub-category does occur, it is parsert as such whatever the context. However, it a given input can be parsed as more than one sub-category. the bottoin-up approach would have to produce them all. even if only one would be predicted top-down. In a systein of limited comprehension. fraginentary recognition is sometines necessary because not all of an input can be recognized, rather than because of intentional ellipsis. Here. it is probably impossible to inake predictions and bottom-up parsing is the only method that is likely to work. As described below. bottom-up stritegles, coupled with suspended parses, are also helpfut in recoynizing interjections and restarts.

\subsection{Pallern Matching}

We have chosen to use a grammar of linear palterns rather than a Irausilinn network becaluse gallerit-mattchung meshus well with boltoin-tip pursing. beciluse 11 facillates recoymition of ullerances with onissions and substitutions. and lecatise it is necessary anywily for the recoynition oi uliomintic phrases.

The grimmat of the parser is a set of rewrite or broduction rules whose

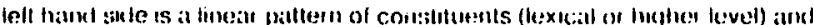
whose right hand side defines a rusult constutumt. Elements of the pattern may be labelled oplional or allow for repeated matches. We make the assumption. certanly true lor the grammar we are presently working with, that the grammar will be semantic ratlier than syntactic. with patterns corresponding to idiomatic phrases or to object and event descriptusts ineanungtul in some limited domain. rather than to general syntactic structures.

Linear patterns fit well with bottom-up parsing because they can be indexed by any of their components. and because. once indexed, it is straightforward to confirm whether a pattern matches input already processed in a way consistent with the way the pattern was indexed.

Patterns hel() with the delection of omissions and substitutions because in either case the relevant pattern can still be indexed by the remaining elements that appear correctiy in the input. and thus the pattern as a whole can be recognized even it some of its elements are missing of incorrect. In the case of substitutions. such a technique can actually hetp locus the spelling correction, proper name recoynition. or vocabulary learning techniques. whichever is appropriatc. by tsolating the substituted input and the pattern constituent which it should have matclied. In effect. this allows the normally bottom-up parsing strategy to go top-down to resalve such substitutions.

In normat left to right processing, it is not necessary to activate all the pallerns inclexed by every new word as it is considered. If a new word is accounted lor by a pattern that has atready been partially inatched by previous input, it is likely that no other palterns need to be indexed and matched for that input. This heuristic alows FlexP's parsing alyorithin to limit the number of patterins it tries to match. We should emphasize. however, that it is a heuristic. and while it has caused us no trouble with the limted-domain grammir we huve been using. it is anclear how well it would transfer to a more complex gramunar. Flexp's algorithm does. however. carry along multiple partial parses in other anbujuous cases. removing the need for any backtracking.

\subsection{Parse Suspension and Continuation}

FlexP einploys the teclinique of suspending a parse with the possibility of later contimuation to help with the reconnition of interjections. restarts. and implicit termmations. The barsing algurithun works lett to sight in a breandh-lirst mamner. If mainuains a set of pirtial parses. each ol which accounts for the input alrealy processud but not yel accourtod lor by a completed purse. The parser altempts to incorporate each new input into ejch of the martial parses. If this is successful. the partial parses are exienulert and inily increase or clecrease in number. If no partial parse can be extendet. the entire set is sivent is a suspended parse.

There are several possitble explanations for input mismatch, i.e. the faiture of tice next input to extend a parse.

- The input could be an implicit termination, i.e. the start of a new top-level utterance, and the previous utterance should be assumed complete.

- llw: "1y uil could be a restart. in which case li.e aclive parse should be abandioned and a new parse started from that point.

- The input could be the start of an interiection. in which case the active parse should be temporarily susnended. and a new parse started for the interjection.

It is not possible, in general, to distinguish between these cases at the time the mismatch occurs. If the active parse is not at a possible ternination point, then input misinatch cannot indicate impticit 
termination, but may indicate eitler restart or interiection. It is necessary to suspend the active parse and wait to see if it is continued at the next input inismatch. On the other hand, if the active narse is at a possible termination point. input mistnatch does not rule out interjection or even restart. In this situation, our algorithin tentatively assumes that there has been an inplicit termination, but suspends the active parse anyway for subsequent potentiat continuation.

Note also that the possibility of iniplicit termination provides justification for the strategy of interpreting each input immediately it is received. If the input signals an inplicit termination, then the user inay well expect the system to respond immediately to the input thus terminated.

\section{Details of Flexp}

This section describes how Flexp achieves the flexibilities discussed earlier. The inplementation described is being used as the parser for an intelligent intertace to a multi-media message system [1]. The intelligence in this interface is concentrated in a //ser Mypent which inediates between the user and the underlying tool system. The Ajent ensures that the interaction goes sinoothly by, annong other things. clecking that the user specifies the operations he wants performed and their parameters correctly and unambiguously. confucting a dialogue with the user if problems arise. The role of Flexr' as the Agent's parser is to transiorn the user's input into the internal representitions employed by the Agent. Usually this input is a refuest for action by the tool or a description of objects known to the tonl. Our examples are drawn from that context.

\subsection{Preliminary Example}

Sippose the user types

display new messages

Interpretation begins as soon as any input is available. The first word is used as an index into the store of rewrite rules. Each rule gives a pattern and a structure to be profluced when litn paltern is mitched. The components of the structure are built from the structures or words which match the elements of the paltern. The word "display" indexes the rule:

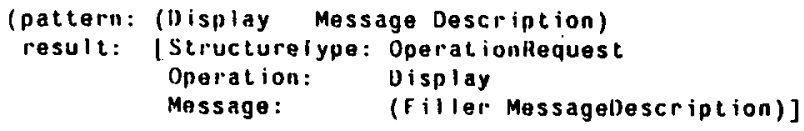

Using this rule llie parser constructs the partial parse tree

(Display Messagevescription)

We call the partially-instantiated pattern which labels the upper node a hypothosis. It represents a possible interpretation for a segment of input.

The next word "new" does not directly match the hypothesis, but since "new" is a Msgadj (an adjective which can modily a description of a message), it indexes the rule:

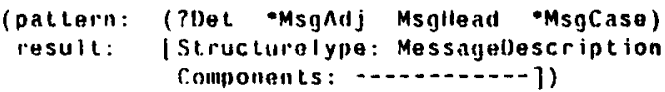

Here. "?" means optional, and "." means repeatable. For the sake of clarity, we have omitted other prefixes which distinguish between terminal and non-terinimat pattern elements. The result of this rule lits the current hypothesis. so extends the parse as follows:<smiles>[AsH3]I</smiles>

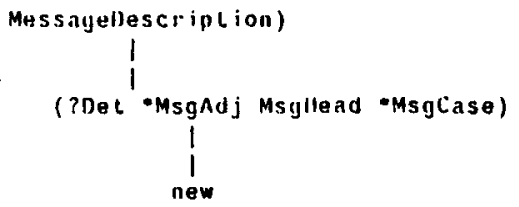

The hypolluesis is not yol fully confirmod even llough all the clements are

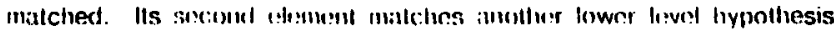
which is only intcompletuly matched. This lower pallem betiones the

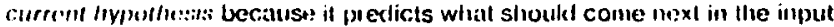
stream.

The third input matclies the category Mssytlead (head noun of a messinge (lescirintion) and so fits the current hypothesis. Thus match tills the last non-uptional slot in that pattern. By cluing so it makes the current hypothesis and its parent pattern potentially complete. When the parser finds a potentially complete phrase whose result is of interest to the Agent (and the parent phrase in this example is in that category), the result is constructed and sent. However. since the parser has not snen a tormination signal, this parse is kejl ac.live. Ilie mput jotll su lal may be only a prefix lor some longer utterance such as "display new inessages about $\wedge D A$ ". In this case "about ADA" would be recognized as a inatch for MsyCase (a prepositional phrase that can be part of a message description), the parse would be extended. and a revision of the previous structure semt to the Agent.

\subsection{Unrecognized Words}

When an input word cannot be lound in the dictionary, spelling correction is attempted in a background process which runs at lower priority than the parser. The input word and a list of possibilities derived from the current hypothesis are passed as arguments. For example:

display the new inessaegs

produces the partial parse
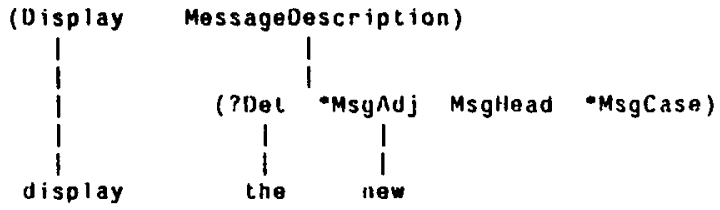

The lower pattern is the current hypothesis and has two elements eligible to match the next input. Another MsyAdi could be matched. A match for MsyHead would also fit. Both elements have associated lists of keywords known to occur in phrases which match them. The one for MsgHead incluktes the word "messages". and the spelling corrector passes this back to the parser as the most likely interpretation.

In some cases the spelling corrector produces several likely alternatives. The parser hanclles such anbiguous words using the same mechanisıns which accollmonodite plirases wilh ambiguous interpretations That is. allemative interpretations are carried along until there is enough invut to discriminite those which are plausible from those which are not. Ilte details are given in the ne:xt section.

The user may also correct the input text himself. These? changes are handle! in much the siune way as those proposed by the spelling corrector. Ot course, these user-supplied changes are given priority, and

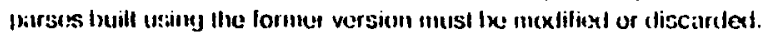

Spelliny correction is rum as a separate. lower priority process because a reasonable pirse may be produced evell without a proper interpretation for the unknown word. Since spelling correction can involve rather time-consuming searches, this work is best done when the parser has.no belter alternatives to explore.

\subsection{Ambiguous Input}

In the first example there was only one hypothesis about the structure of the input. More generally, there may be several hypotheses which provide competing interprelations aboul what has already beten seen and what will appear next. Until these partial parses are lound to be inconsistent with the actual iuput, they are carried along as part of the active purst. Therelore the active parse is a sel of partial parse trees each 
efficiency required for real-time response. but could conceivably fail to find appropriate parses. We have not encountered such circumstances with the surall domain-specilic semantic gramınar we have been using.

\subsection{Flexible Matching}

The only llexibitity described so lar is that allowed by the optional elements of patterns. If omissions can be anticipated. allowances may be built unlu the granulatr. In this sechon we show how other ornissions may be hillullent and othel flexitsililes achieved by allowing atcitional freedom in the waly all itein is allowed to inatch a pattern. There are two ways in with a top-level hypothesis about the overall structure of the input so far and a current hypothesis concerning the next input. The actual umpiementation allows sharing of common structure among competing hypotheses and so is more ellicient than this description suggests.

\section{The input}

were there any inessayes on.......

could be completed by giving a date ("... on Tuesday") or a topic ("... on $A D A ")$. Conscouently, the sub-phrase "any messages on" results in two partial parses:

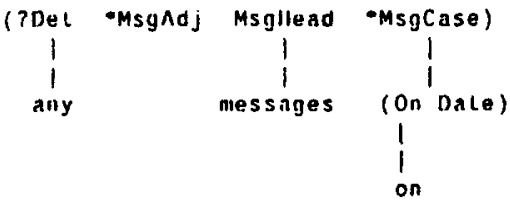

and

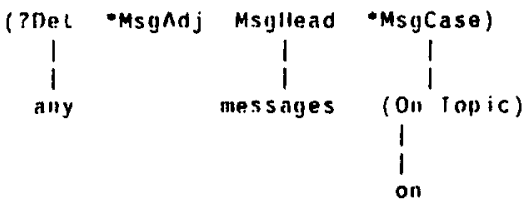

If the next inpul were "Thesdily" it woukt be consislent with lhe first parse. bul not the seconk. Since one of the allormatives toes accoult for the

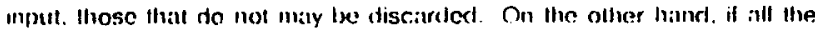
partial parsis fan to match llws innut. Ollnen action is taken. We consiner alled siluthous in the section un suspendert parses

As a yenteral strategy. we carry sevetal possite interpretalıons only as long as there is no clear bost alternative. In marticutar no llexible parsiny techniques are uset to summort parses for which there are plausible allermatives unter normal bitrsing. This heuristic helps achieve the which the malching criteria inay be relaxed. namely

- relax consistency constraints. e.g. number agreement

\section{- allow oul ol order inatches}

Consistency constraints are predicates which are attached to rules. They assert relationships which must hold among the items which fill the pattern. These constraints allow context-sensilive constructions in the grammar. Such predicates are commonly used ior simalar purposes by ATN parsers $|14|$ and the flexibility achieved by relaxing these constraints has been explored velore $[13$. The technique fits sinoothiy into FlexP but has not ictually been needed or used in our current application.

On the other hand. nut of order matching is essential for the parser's anuroacth to errors of omission. Iransposition. and substitution. Even when strkfly inte: proted! several siements of a paltcrn may be eliuble to match the next input item. For example. in the pattern for a MessugeDescription

$$
\text { (PUet -Msgndj Msgllend -MsgCase) }
$$

each of the lirst three efements is multally eligible but the last is not. On the other hillud. unce Msyllead has been matcleat onty the last elentent is eliyible under the strict interpretation of the pattern.

\section{Consicter the input}

display new ituUl ADA

The list two words parse normally lo produce

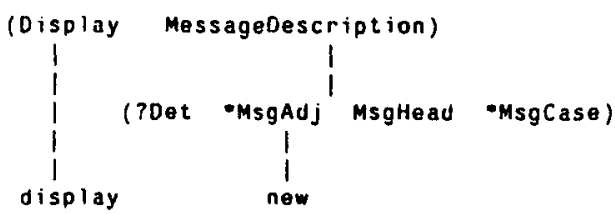

The next word toes not fit that hypothesis. The two eligible elements predict either another messaye anjective or a MsgHead. The word "about" does not match etther of these, nor can the parser construct any path to thein tising intermerliate hypotheses. Since there are no other partial parses available to account for this input. and since normal matching fails. flexible matching is tried.

First. previously skipped elements are compared to the input. In this example. the element ?Det is considered but does not match. Next, elements to the right of the eligible elements are considered. Thus MsgCase is considered even though the non-oplional element MsgHead has not been matched. This succeeds and allows the partial parse to be extended to

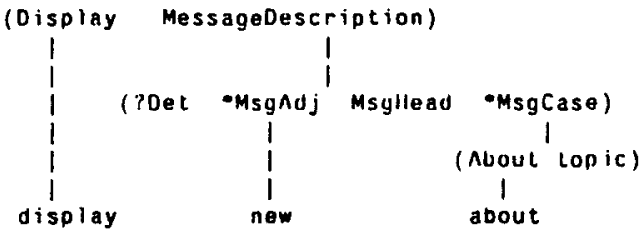

which correctly predicts the final input item.

Unrecognizable substitutions are also handled by this mechanism. In the pirase

display the new stuff about ADA

the word "stulf" is not found in the dictionary so spelling correction is tried but does not produce any plausible allernatives. While spelling correction is uncterway. the remaining inputs can be parsed by simply oinitting "stufl" and using the flexible matching procesture. Transpusilons are handled through one application of llexible inatehing if the element of the iransonserd pair is optional. iwo applicalions if not.

\subsection{Suspendco Parses}

Interlections are more cominon in spoken than in wi iell langlaige but do occur in typext input sumetines. To deal will such inuut. our design allows for blocked parses to be suspended rather than merely discarded.

Users. especially novices. may embeltisht their input with words and phrases that do rat provide essential information and cannot be specifically antıcipatec, Consider $t$, vo examples:

display please mossages dated June 17 display for me messages dated June 17

In the first case. the inierjected word "please" could be recognized as a conminon moise phrase which means nothing to the Ayent except possibly to suyyust that the user is a novice. The second example is more difficult. Both worts of the interiectert phrase can appear in a number of logitimate and meanngful constru:!un Is: they cannot be ignored so easily. 
For the latter example. parse suspension works as follows. After the first word, the active parse contains a single partial parse:

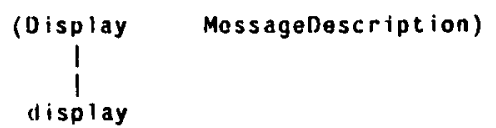

The next word does not fit this hypothesis, so it is suspended. In its place a new active parse is constructed. It contains several partial parses including

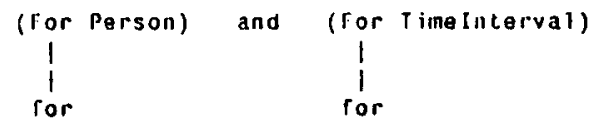

The next word confirms the first of these. lut the lourth word "messicges" does not. When the parser finds that it cannot extend the active parse, it consiclers the suspended parse. Since "messages" fits, the active and suspended parses are exchanged and the remainder of the input processed normally, so that the parser recognizes "display messages dated June 17 " as if it had never contained "for me".

\section{Conclusion}

When people use language naturially, they make inistakes and employ economies of expression that. often restlt in language which is unyrammatical by strict standards. In particular. such grammatical deviations will infevitatbly occur in the input of a computer system which allows its user lo comploy natural languitye. Sucli a compoter system must.

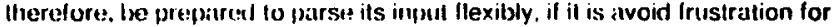
its user.

In this panper, we have attempted In outtine the main kinds of flexibility a natural language parser intended lor natural use slould provide. We also described a botton-up pattern-matching parser. Flexp. which exhibits these licxibilities, and which is suilable for restricted natural linguage inpul to a limited-domain system.

\section{References}

1. Ball, J. E. and Hayes, P. J. Representation of Task-independent Knowledge in a Gracefully Interacting User Interiace. Tech. Rept. Carnegie-Mellon University Computer Science Department, 1980.

2. Bobrow. D. G., Kaplan, R. M., Kay. M.. Norman D. A., Thompson, H., and Winograd. T. "GUS: a Frame-Driven Dialogue System." Artilicial Infelligence 8 (1977), 155-173.

3. Burton. R. R. Semantic Gramınar: An Engineering Technique for Constructing Natural Language Understanding Systems. BBN Report 3453. Bolt. Beranek. and Newman. Inc., December, 1976.

4. Carbonell, J. G. Towards a Self-Extending Parser. Proc. of 17th Annual Meeting of the Assoc. Ior Comput. Ling.. La Jolla, Ca. August, 1979, pp. 3-7.

5. Carbonell, J. G. Subjective Understanding: Computer Models of Belief Systems. Ph.D. Th.. Yale University, 1979.

6. DeJong, G. Skimming Stories in Aeal-Time. Ph.D. Th., Computer Science Dept., Yale University, 1979.

7. Hayes, P. J., and Feddy, R. Gracelul Interaction in Man-Machine Conmunication. Proc. Sixth Int. Jt. Conf. on Artificial Intelligence. Tokyo, 1979, pp. 372-374

B. Hendrix, G. G. Human Engineering for Applied Natural Language Processing. Proc. Filth int. Jt. Cont. on Artificial Intelligence, MIT, 1977, pp. 183-191.
9. Kaplan, S. J. Cooperative Pesponses from a Porlable Nalural

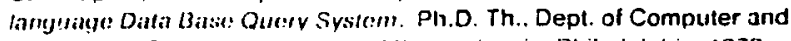
Intormation Science. University of l'ems

10. Kwasny. S. C. and Sondheimer. N. K. Ungraminaticality and Extra-Grammaticality in Natural Language Understanding Systems. Proc. of 17 in Annual Meeting of the Assoc. for Comput. Ling., La Jolla, Ca. August. 1979, pp. 19-23.

11. Paukison. R. C., Colby. K. M., and Faught. W. S. "Conversationa Language Comprehension Using hiregrated Pattern-Matching and Parsıng." Artheial Intelligence (1977), 111-134.

12. Waltz. D. L. "An Finglish Languaye Question Answering Systam for a Large Relational Dala Base." (Comm. ACM 21.7 (1978). 526-539.

13. Weischedel. A. M. and Black. J. Responding to Potentially Unparseable Sentences. Tech. Rept. 79/3. Dept. of Computer and Inforination Sciences, Iniversity of Delaware, 1979

14. Woods. W. A. "Transition Network Grammars for Natural Language Analysis." Comm. ACM 13, 10 (October 1970), 591-606.

15. Woods. W. A., Kaplan. R. M., and Nasil-Webber, B. The Lunar

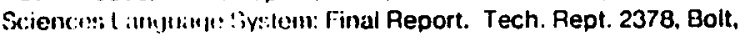
Beranek, and Newman, Inc., 1972 
